\title{
Gas-Phase Infrared Spectrum of the Protonated Water Dimer: Molecular Dynamics Simulation and Accuracy of the Potential Energy Surface
}

Joachim Sauer* and Jens Döbler ${ }^{[a]}$

Dedicated to Professor Michele Parrinello on the occasion of his 60th birthday.

The long-awaited observation of the infrared multiphoton dissociation (IRMPD) spectrum of the protonated water dimer

[a] Prof. Dr. J. Sauer, Dr. J. Döbler Institut für Chemie, Humboldt-Universität Unter den Linden 6, 10099 Berlin (Germany) Fax: (+ 49) 30-2093-7136

E-mail:sek.qc@chemie.hu-berlin.de

$\square$ Supporting information for this article is available on the WWW under http://www.chemphyschem.org or from the author. 
$\mathrm{H}_{5} \mathrm{O}_{2}{ }^{+}$in the $500-2000 \mathrm{~cm}^{-1}$ region (in which the modes of the bridging proton are expected) by Asmis et al. ${ }^{[1]}$ has raised questions $^{[2,3]}$ about the assignment ${ }^{[4]}$ of the observed bands and stimulated more experimental work. ${ }^{[3,5,6]}$ Most recently, infrared predissociation (IRPD) spectroscopy has been applied to the complex of $\mathrm{H}_{5} \mathrm{O}_{2}{ }^{+}$with $\mathrm{Ar}_{1}^{[5,6]}$ and the spectrum obtained shows some differences to that obtained by IRMPD. Whether these differences are due to the different techniques used, or to perturbation of $\mathrm{H}_{5} \mathrm{O}_{2}{ }^{+}$by $\mathrm{Ar}$ in the complex, is presently not clear.

Here we report molecular dynamics (MD) simulations of the vibrational spectra of $\mathrm{H}_{5} \mathrm{O}_{2}{ }^{+}$, its perdeuterated analogue, $\mathrm{D}_{5} \mathrm{O}_{2}{ }^{+}$, and its complex with $\mathrm{Ar}, \mathrm{H}_{5} \mathrm{O}_{2}{ }^{+} \cdot \mathrm{Ar}$, on potential energy surfaces (PES) obtained by Møller-Plesset second-order perturbation theory (MP2) with a correlation-consistent basis set (ccpVTZ) and discuss the accuracy of different potential energy surfaces previously used.

We calculate harmonic vibrational frequencies at the $\operatorname{CCSD}(T) / c c-p V T Z$ level using the ACES-II code. ${ }^{[7]}$ This is the best harmonic result obtained by analytic differentiation published to date. It avoids the unbalanced TZ2P basis set of a previous B-CCSD(T) calculation. ${ }^{[8]}$ Tables 1 and 2 (see also Supporting Information) compare the results obtained with those of previous calculations. The following observations are made for harmonic frequencies: 1) MP2 is a good approximation. When the same basis set is used $\operatorname{CCSD}(\mathrm{T})$ changes the harmonic frequencies by at most $15 \mathrm{~cm}^{-1}$, except for the critical $\mathrm{O}-\mathrm{H}^{+}-\mathrm{O}$ asymmetric stretch, which is shifted by $65 \mathrm{~cm}^{-1}$ to lower wavenumber. 2) Extending the basis set by diffuse functions for all shells at all atoms (aug-cc-pVTZ basis set) at the MP2 level lowers

\begin{tabular}{|llllll|}
\hline \multicolumn{2}{l}{ Table 1. Harmonic vibrational frequencies of the $\mathrm{O}-\mathrm{H}^{+}-\mathrm{O}$ bridge ${ }^{[a]}$. } \\
& $\begin{array}{l}\text { CCSD(T) } \\
\text { cc-pVTZ }\end{array}$ & $\begin{array}{l}\text { MP2 } \\
\text { cc-pVTZ }\end{array}$ & $\begin{array}{l}\text { MP2 } \\
\text { aug-cc-pVTZ }\end{array}$ & $\begin{array}{l}\text { MP2 } \\
\text { cc-pVTZ(aug-O) }\end{array}$ & $\begin{array}{l}\text { MP2 } \\
\text { ref. [4] }\end{array}$ \\
\hline symm O- $\mathrm{H}^{+}-\mathrm{O}$ stretch & 633 & 631 & 627 & 626 & 628 \\
asymm O- $\mathrm{H}^{+}-\mathrm{O}$ stretch & 896 & 961 & 884 & 904 & 1054 \\
$\mathrm{O}-\mathrm{H}^{+}-\mathrm{O}_{x}$ bend & 1493 & 1485 & 1484 & 1473 & 1435 \\
$\mathrm{O}-\mathrm{H}^{+}-\mathrm{O}_{y}$ bend & 1572 & 1557 & 1557 & 1551 & 1524 \\
\hline
\end{tabular}

[a] See Supporting Information for a complete list of frequencies and intensities. the critical $\mathrm{O}-\mathrm{H}^{+}-\mathrm{O}$ asymmetric stretch by as much as $77 \mathrm{~cm}^{-1}$, but changes all other frequencies by less than $25 \mathrm{~cm}^{-1}$. 3) Augmentation with diffuse functions on the $\mathrm{O}$ atoms only [ccpVTZ(aug-O)], as motivated by computational savings lowers the $\mathrm{O}-\mathrm{H}^{+}-\mathrm{O}$ asymmetric stretch by $57 \mathrm{~cm}^{-1}$. 4) The recent fit ${ }^{[9]}$ of the CCSD(T)/cc-pVTZ PES (HBB-Fit) yields harmonic frequencies for the $\mathrm{O}-\mathrm{H}^{+}-\mathrm{O}$ asymmetric stretch and the terminal $\mathrm{OH}$ stretches (ref. [9]; Table 1, last column) that are 35 and 39$44 \mathrm{~cm}^{-1}$, respectively, lower than the present analytic results. 5) The OSS3(p)-Fit ${ }^{[10]}$ of the MP2/cc-pVTZ(aug-O) PES used for the $4 \mathrm{D}$ and $\mathrm{VCl}$ calculations ${ }^{[2]}$ shows frequency deviations from the direct MP2/cc-pVTZ(aug-O) calculation of $47 \mathrm{~cm}^{-1}$ for the $\mathrm{O}-\mathrm{H}^{+}-\mathrm{O}$ asymmetric stretch, $46 \mathrm{~cm}^{-1}$ for the $\mathrm{O}-\mathrm{H}^{+}-\mathrm{O}_{y}$ bend and $110 \mathrm{~cm}^{-1}$ for one of the outer $\mathrm{H}-\mathrm{O}-\mathrm{H}$ bends (we refer to the global-minimum data in Table 3 of ref. [11] and Table III of ref. [2]). 6) The TZP (on O), DZP (on H) basis set used in ref. [4]

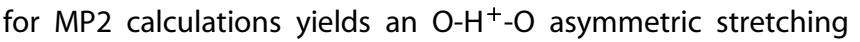
frequency which is $87 \mathrm{~cm}^{-1}$ higher than the MP2/cc-pVTZ result (and as much as $158 \mathrm{~cm}^{-1}$ higher than the $\operatorname{CCSD}(T)$ result), while the $\mathrm{O}-\mathrm{H}^{+}-\mathrm{O}_{x, y}$ bends are too low by 58 and $48 \mathrm{~cm}^{-1}$ (cf. Table I in ref. [4]).

The harmonic approximation is not adequate for strongly hydrogen bonded systems, and in the light of the approximations on the PES we comment on previous quantum calculations that take anharmonicities into account. The quality of the dynamic description depends on the number of degrees of freedom included, on the choice of coordinates and on the treatment of couplings. Normal modes as used in the CC$\mathrm{VSCF}^{[12]}$ and $\mathrm{VCl}$ calculations ${ }^{[2,11]}$ describe regions outside the reference configuration poorly and become strongly coupled. For example, the CC-VSCF and $\mathrm{VCl}$ models describe the outer symmetric and asymmetric $\mathrm{OH}$ stretching vibrations of the two proton-bonded water molecules very poorly (Table 2 ). The predicted anharmonicities are much too large, and the fundamentals too low. In contrast, secondorder perturbation theory (PT),

\begin{tabular}{|c|c|c|c|c|c|c|c|}
\hline & & $\begin{array}{l}\operatorname{CCSD}(T) \\
\text { fund } \\
\text { (anharm) } \\
\text { this work }\end{array}$ & $\begin{array}{l}\text { HBB-Fit } \\
\text { DMC } \\
\text { fund } \\
\text { (anharm) } \\
\text { ref. [22] }\end{array}$ & $\begin{array}{l}\text { MP2/cc-pVTZ } \\
\text { PT } \\
\text { fund } \\
\text { (anharm) } \\
\text { this work }\end{array}$ & $\begin{array}{l}\text { MP2/TZP } \\
\text { CC-VSCF } \\
\text { fund } \\
\text { (anharm) } \\
\text { ref. [12] }\end{array}$ & $\begin{array}{l}\text { OSS3-Fit } \\
\text { VCI } \\
\text { fund } \\
\text { (anharm) } \\
\text { ref. [11] }\end{array}$ & $\begin{array}{l}\text { Obsd. } \\
\text { fund } \\
\text { ref. [23] }\end{array}$ \\
\hline \multirow[t]{5}{*}{$\mathrm{H}_{5} \mathrm{O}_{2}^{+}$} & $\mathrm{H}-\mathrm{O}-\mathrm{H}$ bend, in-phase & $1614^{[a]}$ & & $1599(-110)$ & $1662(-50)$ & $1646(-70)$ & \\
\hline & OH symm stretch, out-of-phase & $3620^{[a]}$ & $3511(-233)$ & $3613(-163)$ & $3518(-291)$ & $3319(-381)$ & 3609 \\
\hline & $\mathrm{OH}$ symm stretch, in-phase & $3629^{[a]}$ & $3552(-193)$ & $3622(-163)$ & $3593(-224)$ & $3427(-369)$ & \\
\hline & $\mathrm{OH}$ assym stretch, out-of-phase & $3697^{[a]}$ & $3652(-180)$ & $3701(-179)$ & $3577(-343)$ & $3468(-415)$ & 3684 \\
\hline & $\mathrm{OH}$ stretch, in-phase & $3696^{[a]}$ & $3652(-180)$ & $3701(-180)$ & $3579(-342)$ & $3472(-422)$ & 3684 \\
\hline \multirow[t]{3}{*}{$\mathrm{H}_{2} \mathrm{O}$} & $\mathrm{H}-\mathrm{O}-\mathrm{H}$ bend & $1616(-51)$ & & $1600(-30)$ & $1548(-67)$ & & 1595 \\
\hline & $\mathrm{OH}$ symm stretch & $3683(-175)$ & & $3702(-169)$ & $3700(-154)$ & & 3657 \\
\hline & $\mathrm{OH}$ assym stretch & $3775(-189)$ & & $3812(-181)$ & $3798(-196)$ & & 3756 \\
\hline
\end{tabular}


which uses third- and fourth-order force constants as implemented in the ACES-II code, ${ }^{[13]}$ explains the observed frequencies in the $\mathrm{OH}$ stretching region satisfactorily (Table 2). Diffusion Monte Carlo (DMC) yields virtually identical anharmonicities for the asymmetric $\mathrm{OH}$ stretches (Table 2), but larger anharmonicities (and poorer agreement with observed fundamentals) for the symmetric stretches than perturbation theory. This failure of the CC-VSCF and VCI treatments raises doubts about their ability to describe the even more difficult situation in the $\mathrm{O}-\mathrm{H}^{+}-\mathrm{O}$ bridge.

The Cartesian coordinates used in $(2 \times 2)$-dimensional calculations ${ }^{[4]}$ and also adopted later ${ }^{[2]}$ for four-dimensional calculations are less coupled and may be better suited than normal modes for the $\mathrm{O}-\mathrm{H}^{+}-\mathrm{O}$ bridge. The $(2 \times 2) \mathrm{D}^{[4]}$ and $4 \mathrm{D}^{[2]}$ treatments not only couple the four coordinates of the $\mathrm{O}-\mathrm{H}^{+}-\mathrm{O}$ bridge differently, they also differ in how these four coordinates are coupled to the remaining ones of the whole system. While the $(2 \times 2)$ treatment ${ }^{[4]}$ attempts to take some of this coupling implicitly into account, since the four-dimensional PES is calculated for relaxed (optimized) values of all other coordinates of the system (under the only constraint of fixed mutual orientations of the two water molecules), the $4 \mathrm{D}$ calculation of ref. [2] uses a PES which is derived from the full-dimensional fitted PES "by freezing all coordinates outside the $\mathrm{O}-\mathrm{H}^{+}-\mathrm{O}$ fragment at their equilibrium values".

In spite of different approximations, the $(2 \times 2) \mathrm{D}_{1}^{[4]} \mathrm{CC}$ $\mathrm{VSCF}^{[12]} 4 \mathrm{D}^{[2]}$ and $\mathrm{VCl}^{[2]}$ models agree in the following for the vibrations of the $\mathrm{O}-\mathrm{H}^{+}-\mathrm{O}$ bridge: 1 ) The splitting between the $\mathrm{O}-\mathrm{H}^{+}-\mathrm{O}_{y}$ and $\mathrm{O}-\mathrm{H}^{+}-\mathrm{O}_{x}$ bends is small $\left(58,52,16,11 \mathrm{~cm}^{-1}\right)$. 2) Compared to the harmonic spectrum the $\mathrm{O}-\mathrm{H}^{+}-\mathrm{O}$ asymmetric stretch is shifted up $\left(104,338,328,57 \mathrm{~cm}^{-1}\right)$ and the O$\mathrm{H}^{+}-\mathrm{O}$ bends are shifted down $(467 / 498,69 / 58,158 / 161,117 /$ $\left.125 \mathrm{~cm}^{-1}\right)$. 3) The $(2 \times 2) \mathrm{D}^{[4]}$ and $4 \mathrm{D}^{[2]}$ calculations both predict two bands in addition to the fundamentals: an $\mathrm{O}^{-} \mathrm{H}^{+}-\mathrm{O}$ symmetric stretching overtone in the region of the $\mathrm{O}-\mathrm{H}^{+}-\mathrm{O}$ asymmetric stretch and $\mathrm{O}-\mathrm{H}^{+}-\mathrm{O}$ bends, at 1158 and $1120 \mathrm{~cm}^{-1}$, respectively, and a combination of the $\mathrm{O}-\mathrm{H}^{+}-\mathrm{O}$ symmetric and asymmetric stretches in the region of the outer $\mathrm{H}-\mathrm{O}-\mathrm{H}$ bends, at 1671 and $1682 \mathrm{~cm}^{-1}$, respectively.

We conclude that the largest uncertainty of the $(2 \times 2) D$ quantum results ${ }^{[4]}$ comes from the basis set used for calculating the PES. Assuming that this error is largely in the harmonic part, estimates for the $\mathrm{O}^{-} \mathrm{H}^{+}-\mathrm{O}$ asymmetric stretching fundamental can be obtained by combining the anharmonic correction from the $(2 \times 2) \mathrm{D}$ quantum results ${ }^{[4]}\left(+104 \mathrm{~cm}^{-1}\right)$ with the MP2/a-ccVTZ harmonic result $\left(884 \mathrm{~cm}^{-1}\right)$. Calculations made with the cc-pVTZ basis set indicate that $\operatorname{CCSD}(\mathrm{T})$ may lower the harmonic MP2 value by $65 \mathrm{~cm}^{-1}$. Hence, the $\mathrm{O}-\mathrm{H}^{+}-\mathrm{O}$ asymmetric stretch is expected between 923 and $988 \mathrm{~cm}^{-1}$, which supports - as already proposed by Dai et al. ${ }^{[2]}$-its assignment to line $b$ of the observed spectrum.

Incidentally, for the present type of symmetric protonbonded systems, the harmonic MP2/cc-pVTZ result $\left(961 \mathrm{~cm}^{-1}\right)$ seems to be a good predictor for the observed band maximum of the asymmetric $\mathrm{O}-\mathrm{H}^{+}-\mathrm{O}$ stretch $\left(921 \mathrm{~cm}^{-1}\right)$, because anharmonic corrections (on the order of $+104 \mathrm{~cm}^{-1}$ ) and changes in the harmonic frequency due to changes of the PES (on the order of $-170 \mathrm{~cm}^{-1}$ ) partially outweigh each other. Other examples are $\mathrm{D}_{5} \mathrm{O}_{2}^{+}$with $692 \mathrm{~cm}^{-1}$ (MP2/cc-pVTZ harmonic) versus $697 \mathrm{~cm}^{-1}$ (observed band $\left.\mathrm{b}^{\prime}\right)^{[1]}$ and the proton-bonded dimethyl ether dimer with $823 \mathrm{~cm}^{-1}$ (MP2/cc-pVTZ, G. von Helden, personal communication) versus $810 \mathrm{~cm}^{-1}$ observed. ${ }^{[14]}$

An alternative method with full coupling and full anharmonicity is the calculation of the IR spectra as the Fourier transform (FT) of the dipole autocorrelation function from trajectories generated by ab initio MD. Its limitation is that quantum

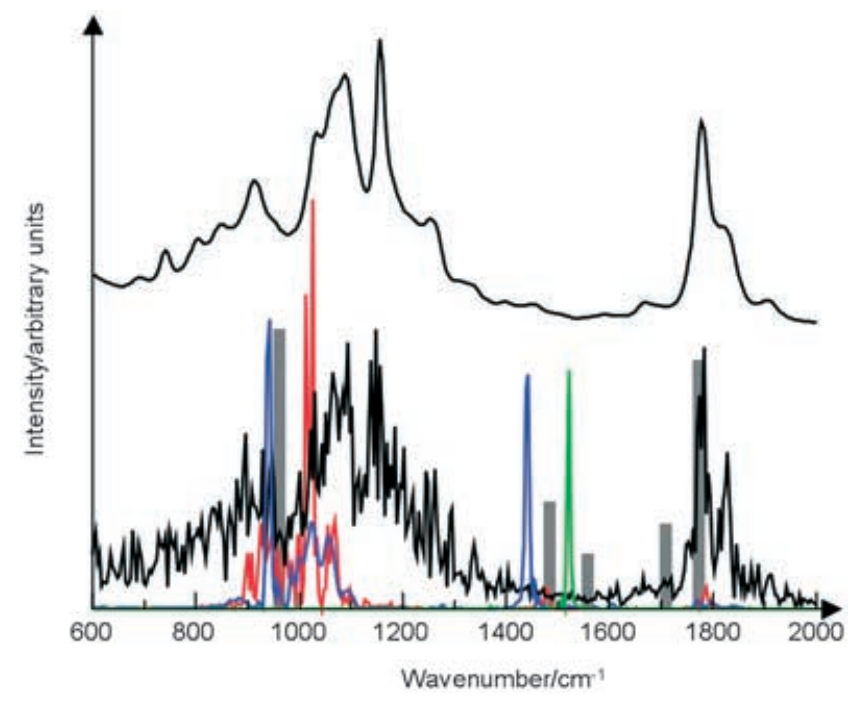

Figure 1. Infrared spectrum of $\mathrm{H}_{5} \mathrm{O}_{2}{ }^{+}$obtained as Fourier transform of the dipole autocorrelation function. The grey sticks are the harmonic results. The red spectrum was obtained by exciting selectively the asymmetric $\mathrm{O}$ $\mathrm{H}^{+}-\mathrm{O}$ stretching mode, and the blue and green spectra by exciting selectively the $\mathrm{O}-\mathrm{H}^{+}-\mathrm{O}_{x, y}$ mode. The smoother upper curve is the spectrum obtained by the maximum-entropy method ${ }^{[24]}$ (200 poles).

effects on the motion of the nuclei are not included. Figure 1 shows results of such a simulation for the MP2/cc-pVTZ PES (Turbomole code, ${ }^{[15-17]}$ NVE ensemble, time step $0.484 \mathrm{fs}$, simulation time $4.35 \mathrm{ps}$, initial velocities randomly chosen at equilibrium structure by assuming a Boltzmann distribution, temperature about $350 \mathrm{~K}$ ) together with the harmonic stick spectrum. This spectrum is an average over six trajectories. All other spectra are averages over two trajectories that differ only in the direction of the initial velocities. The spectrum is very similar to those previously obtained by $\mathrm{MD}$ on $\mathrm{MP}^{2}{ }^{[4]}$ or DFT PES ${ }^{[18]}$ Figure 2 shows the same for $\mathrm{D}_{2} \mathrm{O}_{5}{ }^{+}$. The band around $1800 \mathrm{~cm}^{-1}\left(1300 \mathrm{~cm}^{-1}\right.$ for $\left.\mathrm{D}_{2} \mathrm{O}_{5}{ }^{+}\right)$is due to the $\mathrm{H}-\mathrm{O}-\mathrm{H}$ bends of the two proton-bound $\mathrm{H}_{2} \mathrm{O}$ molecules and is unequivocally assigned to band e $\left(\mathrm{e}^{\prime}\right.$ for $\left.\mathrm{D}_{2} \mathrm{O}_{5}{ }^{+}\right)$. The bands in the region $850-1300 \mathrm{~cm}^{-1}\left(600-950 \mathrm{~cm}^{-1}\right.$ for $\left.\mathrm{D}_{2} \mathrm{O}_{5}{ }^{+}\right)$correspond to observed bands $b-d\left(b^{\prime}-d^{\prime}\right)$.

Figure 1 also shows spectra obtained from MD trajectories that have been initiated by selective displacements along individual normal modes of the $\mathrm{O}_{-} \mathrm{H}^{+}-\mathrm{O}$ unit instead of random velocities. Initial displacements along the $\mathrm{O}-\mathrm{H}^{+}-\mathrm{O}_{x, y}$ bends (perpendicular to the $\mathrm{O}-\mathrm{O}$ axis) yield spectra (green and blue curves) with peaks at 1450 and $1520 \mathrm{~cm}^{-1}$, slightly below their harmonic values, shown as grey sticks in Figure 1. This indi- 


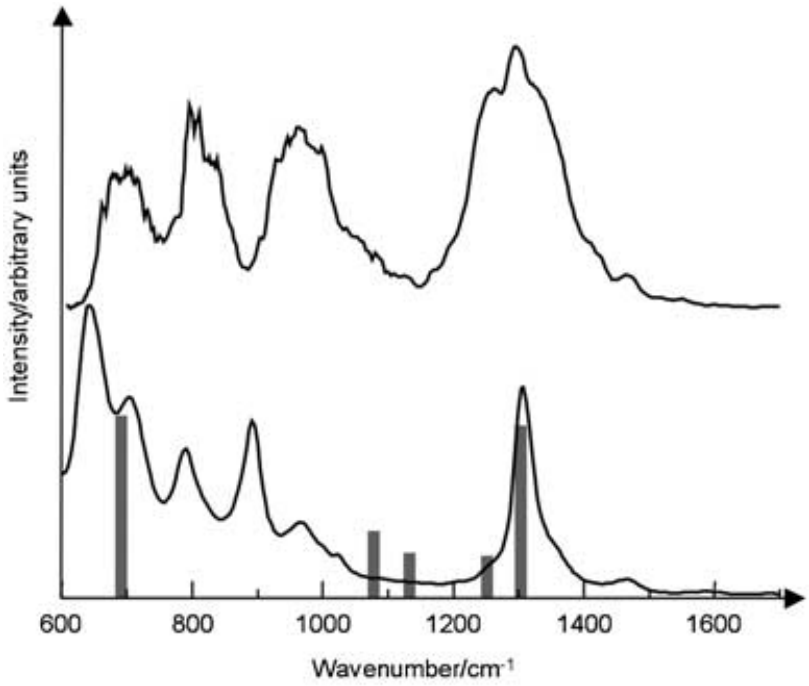

Figure 2. Simulated infrared spectrum of $\mathrm{D}_{5} \mathrm{O}_{2}{ }^{+}$(bottom, harmonic spectrum shown as sticks) compared to the IRMPD spectrum of $\mathrm{D}_{5} \mathrm{O}_{2}{ }^{+}$(top). ${ }^{[1]}$

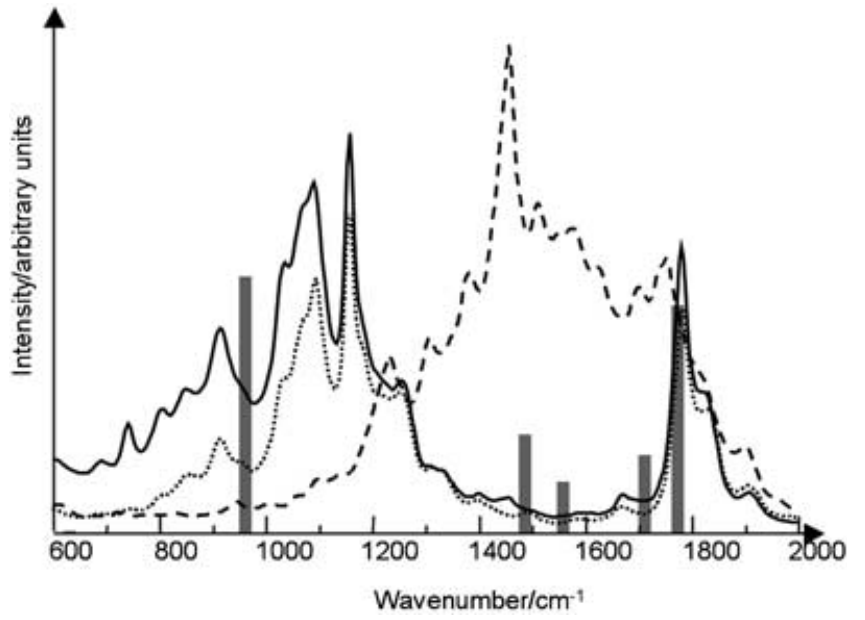

Figure 3. Infrared spectrum of $\mathrm{H}_{5} \mathrm{O}_{2}{ }^{+}$(solid line, harmonic spectrum shown as sticks) and Fourier transform of the autocorrelation function of the velocity of the bridging proton only. Dotted: $z$ component, dashed: $x+y$ components (maximum entropy ${ }^{[24]}$ with 200 poles applied to all spectra).

$\mathrm{H}_{5} \mathrm{O}_{2}{ }^{+}$to a noticeable extent. The dashed curve has high intensities in the $1300-1650 \mathrm{~cm}^{-1}$ region, where the $\mathrm{O}-\mathrm{H}^{+}-\mathrm{O}_{x, y}$ bending fundamentals have been identified (see Figure 1).

There are two important conclusions from the above analysis: 1) The $\mathrm{O}-\mathrm{H}^{+}-\mathrm{O}_{x, y}$ bends do not contribute to the observed IR spectrum. 2) The broad band between 850 and $1300 \mathrm{~cm}^{-1}$ obtains its intensity from motions of the bridging proton in the $z$ direction. Analysis of the MD trajectories shows that these motions cannot be described by the asymmetric $\mathrm{O}-\mathrm{H}^{+}-\mathrm{O}$ stretching normal mode alone, but are also coupled to low-frequency reorientations of the terminal water molecules (torsion and wagging). This was documented in a previous MD study at the DFT level ${ }^{[18]}$ and is also in agreement with the recent analysis of a fitted $\operatorname{CCSD}(\mathrm{T}) /$ aug-cc-pVTZ PES. ${ }^{[9]}$ These findings show that a low-dimensional quantum treat-

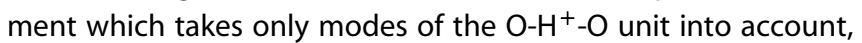
such as the previous $(2 \times 2) \mathrm{D}$ model, ${ }^{[4]}$ cannot reproduce all features of the broad band between 850 and $1300 \mathrm{~cm}^{-1}$. A recent correlation-function quantum Monte Carlo study ${ }^{[19]}$ on the OSS3 potential energy surface also identified states with large transition moments arising from couplings of the asymmetric $\mathrm{O}-\mathrm{H}^{+}-\mathrm{O}$ mode with waggings and torsions of the two water molecules.

Figure 4 shows the simulated IR spectrum of the $\mathrm{H}_{5} \mathrm{O}_{2}{ }^{+} \cdot \mathrm{Ar}$ complex (solid line, bottom). It is virtually identical with the IR spectrum of $\mathrm{H}_{5} \mathrm{O}_{2}{ }^{+}$(dotted line, bottom). In the global minimum structure (Figure 5) Ar binds weakly (8.5$\left.11.3 \mathrm{~kJ} \mathrm{~mol}^{-1}\right)^{[20,21]}$ to $\mathrm{H}_{5} \mathrm{O}_{2}{ }^{+}$in the direction of one of the terminal $\mathrm{O}-\mathrm{H}$ bonds. However, during the $\mathrm{MD}$ run it assumes all possible configurations with respect to the central $\mathrm{O}-\mathrm{H}^{+}-\mathrm{O}$ unit, including all four equivalent $\mathrm{OH}$...Ar positions. While the equilibrium structure exhibits a large shift of almost $250 \mathrm{~cm}^{-1}$ of the harmonic asymmetric $\mathrm{O}-\mathrm{H}^{+}-\mathrm{O}$ stretching frequency to higher wavenumbers (see sticks in Figure 4), this effect averages out in the MD simulations. 


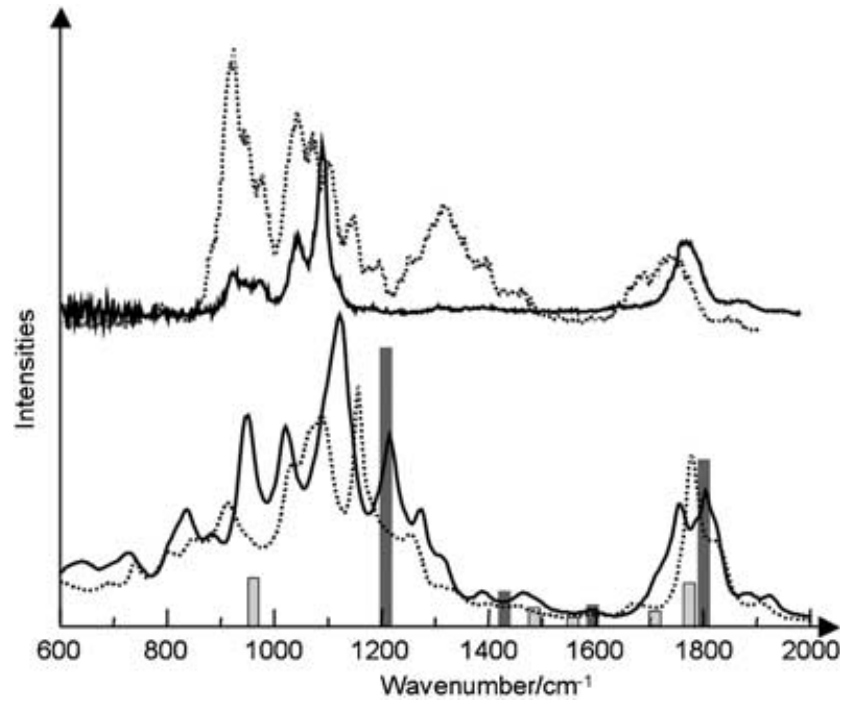

Figure 4. Simulated infrared spectra of $\mathrm{H}_{5} \mathrm{O}_{2}{ }^{+}$(dotted line, bottom) and of the $\mathrm{H}_{5} \mathrm{O}_{2}{ }^{+}$. Ar complex (solid line, bottom) with harmonic spectrum shown as sticks, compared to the IRMPD spectrum of $\mathrm{H}_{5} \mathrm{O}_{2}{ }^{+}$(dotted line, top $)^{[1]}$ and the IRPD spectrum of $\mathrm{H}_{5} \mathrm{O}_{2}{ }^{+}$. $\mathrm{Ar}$ (black, top). ${ }^{[6]}$

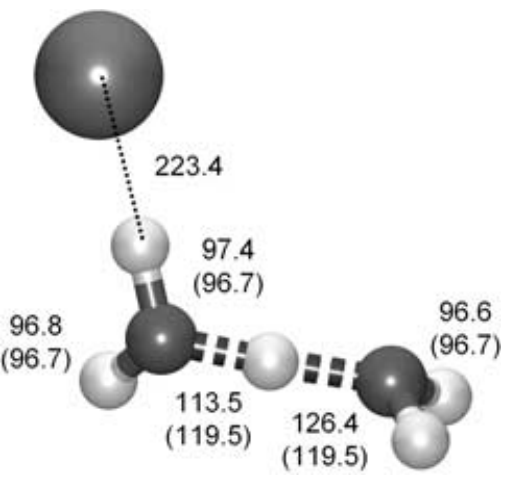

Figure 5. Equilibrium structure of the $\mathrm{H}_{5} \mathrm{O}_{2}{ }^{+} \cdot \mathrm{Ar}$ complex. Bond lengths [pm] and angles $\left[{ }^{\circ}\right]$ in parentheses are for the free $\mathrm{H}_{5} \mathrm{O}_{2}{ }^{+}$ion.

From this comparison we conclude that differences between the IRMPD spectrum. ${ }^{[1]}$ and the IRPD spectrum ${ }^{[5,6]}$ should be due to the different excitation mechanisms and/or different temperatures.

From the present MD simulations we arrive at the following assignments: The band around $1800 \mathrm{~cm}^{-1}$ can safely be assigned to $\mathrm{H}-\mathrm{O}-\mathrm{H}$ bends of the terminal water molecules, the $\mathrm{O}-\mathrm{H}^{+}-\mathrm{O}_{x, y}$ bends (perpendicular to the $\mathrm{O}-\mathrm{O}$ axis) have vanishing IR intensities and should not be seen in the spectra and the bands in the range between 800 and $1300 \mathrm{~cm}^{-1}$ are due to motions of the bridging proton in the $z$ direction, which are coupled to torsions and waggings of the terminal water molecules.

\section{Acknowledgements}

We thank Knut Asmis, Gert von Helden and Mikhail Vener for discussions and for the privilege to read manuscripts prior to publication.

Keywords: ab initio calculations - hydrogen bonds - IR spectroscopy $\cdot$ molecular dynamics

[1] K. R. Asmis, N. L. Pivonka, G. Santambrogio, M. Brümmer, C. Kaposta D. M. Neumark, L. Wöste, Science 2003, 299, 1375-1377.

[2] J. Dai, Z. Bacic, X. Huang, S. Carter, J. M. Bowman, J. Chem. Phys. 2003, $119,6571-6580$.

[3] T. D. Fridgen, T. B. McMahon, L. MacAleese, J. Menaire, P. Maitre, J. Phys. Chem. A 2004, 108, 9008-9010.

[4] M. V. Vener, O. Kühn, J. Sauer, J. Chem. Phys. 2001, 114, 240-249.

[5] J. M. Headrick, J. C. Bopp, M. A. Johnson, J. Chem. Phys. 2004, 121, $11523-11526$.

[6] E. G. Diken, J. M. Headrick, J. R. Roscioli, J. C. Bopp, M. A. Johnson, A. B. McCoy, J. Phys. Chem. A 2005, 109, 1487-1490.

[7] J. Gauss, J. F. Stanton, Chem. Phys. Lett. 1997, 276, 70-77.

[8] E. F. Valeev, H. F. Schaefer III, J. Chem. Phys. 1998, 108, 7197-7201.

[9] X. Huang, B. J. Braams, J. M. Bowman, J. Chem. Phys. 2005, 122, 044308.

[10] L. Ojamäe, I. Shavitt, S. J. Singer, J. Chem. Phys. 1998, 109, 5547-5564.

[11] X. Huang, H. M. Cho, S. Carter, L. Ojamäe, J. M. Bowman, S. J. Singer, J. Phys. Chem. A 2003, 107, 7142-7151.

[12] G. M. Chaban, J. O. Jung, R. B. Gerber, J. Phys. Chem. A 2000, 104, 2772 2779.

[13] J. F. Stanton, C. L. Lopreore, J. Gauss, J. Chem. Phys. 1998, 108, $7190-$ 7196.

[14] D. T. Moore, J. Oomens, L. van der Meer, G. von Helden, G. Meijer, J. Valle, A. G. Marshall, J. R. Eyler, ChemPhysChem 2004, 5, 740-743.

[15] R. Ahlrichs, M. Bär, M. Häser, H. Horn, C. Kölmel, Chem. Phys. Lett. 1989, $162,165-169$.

[16] F. Haase, R. Ahlrichs, J. Comput. Chem. 1993, 14, 907-912.

[17] S. D. Elliott, R. Ahlrichs, O. Kampe, M. M. Kappes, Phys. Chem. Chem. Phys. 2000, 2, 3415.

[18] V. Termath, J. Sauer, Mol. Phys. 1997, 91, 963-975.

[19] H. M. Cho, S. J. Singer, J. Phys. Chem. A 2004, 108, 8691-8702.

[20] Counterposie-corrected MP2/cc-pVTZ yields $8.5 \mathrm{~kJ} \mathrm{~mol}^{-1}$; basis-set extrapolation with the T-Q two-point scheme (ref. [21]) yields $11.3 \mathrm{~kJ} \mathrm{~mol}^{-1}$.

[21] A. Halkier, W. Klopper, T. Helgaker, P. Jorgensen, P. R. Taylor, J. Chem. Phys. 1999, 111, 9157-9167.

[22] A. B. McCoy, X. Huang, S. Carter, M. Y. Landeweer, J. M. Bowman, J. Chem. Phys. 2005, 122, 061101-1-061101-4.

[23] L. I. Yeh, M. Okumura, J. D. Myers, J. M. Price, Y. T. Lee, J. Chem. Phys. 1989, 91, 7319-7330.

[24] W. H. Press, S. A. Teukolsky, W. T. Vetterling, B. P. Flannery, Numerical Recipes, Cambridge University Press, Cambridge, 1992.

Received: February 5, 2005

Published online on July 11, 2005 